\title{
The Influence of Patient and Hospital Characteristics on Inpatient Satisfaction at Beijing District-Level Hospitals
}

\section{Meicen Liu (D) \\ Linlin $\mathrm{Hu}$ \\ Ran Guo \\ Huanqian Wang \\ Man Cao \\ Xinyue Chen \\ Yuanli Liu}

School of Health Policy and Management, Chinese Academy of Medical Sciences \& Peking Union Medical College, Beijing, I00730, People's Republic of China
Correspondence: Linlin Hu

Chinese Academy of Medical Sciences and Peking Union Medical College, 5 Dongdansantiao, Dongcheng District, Beijing, 100730, People's Republic of China

Tel $+86-|3-66| 229049$

Fax +86-65I05830

Email hulinlin@sph.pumc.edu.cn
Purpose: Patient satisfaction is a key indicator of healthcare quality and hospital performance. This study aims to assess inpatient satisfaction at district-level hospitals and explore the determinants of inpatient satisfaction.

Patients and Methods: A total of 1458 adults from inpatient departments of 47 district-level hospitals in 16 districts across Beijing were recruited with a multi-stage stratified sample at Beijing in 2019. Univariate analysis and multivariate logistic regression were used to identify the influence of patient and institutional characteristics on inpatient satisfaction in four domains - administrative process, hospital environment, medical care, hospitalization expenses, and overall satisfaction.

Results: Of the 1458 participants, $577(39.6 \%)$ were men, $581(39.8 \%)$ were over 60 years of age. The average value of satisfaction score measured by a 5-point Likert scale were 4.37, $4.00,4.44,3.89$, and 4.33 for the four domains and overall satisfaction. Patient and institutional characteristics were strongly associated with inpatient satisfaction. Patients with higher educational level were more satisfied with administrative process $(P<0.05)$. Elder patients and patients with worse self-reported health status were less satisfied with hospital environment $(P<0.05)$. Female, higher monthly family income and Urban Employees Basic Medical Insurance were positively associated with patient satisfaction in hospitalization expenses $(P<0.05)$. And patients receiving care in suburban hospitals were less satisfied with administrative process, hospital environment and overall satisfaction $(P<0.05)$. Patients receiving care in Traditional Chinese Medicine hospitals were more satisfied with medical care and expenses but less satisfied with environment $(P<0.05)$. Chronic disease and hospital grade were not significantly associated with satisfaction in all domains.

Conclusion: Patient satisfaction was influenced by demographic characteristics and hospital features. These determinants should be considered in hospital evaluation.

Keywords: patient satisfaction, hospital care, district-level hospitals, health service

\section{Introduction}

Patient satisfaction as a key indicator of medical care quality and hospital performance increasingly has gained recognition in a variety of countries. ${ }^{1,2}$ Many studies and systematic reviews have revealed a positive association between patient satisfaction and clinical outcomes. ${ }^{3,4}$ In China, hospital administrators, in pursuit of patientcentered and high-quality health care, have grown increasingly concerned about whether or not their patients are satisfied with the care and service received. In 2018, the National Health Commission of China (NHCC) officially incorporated patient satisfaction into performance evaluations for public hospitals. 
The medical care system in China consists of regional medical centers, city-level hospitals, district or countylevel hospitals, and community-level health institutions. District-level hospitals usually treat a large number of patients with common diseases. They account for most medical services provided to the local population. Previous studies primarily have focused on large hospitals or community-level health institutions and less on districtlevel hospitals. ${ }^{5-9}$ This study focuses on patient satisfaction and the factors that shape it in district-level hospitals.

Patient satisfaction reflects the difference between patient's expectations and their actual experiences. ${ }^{10}$ Previous studies have identified many factors that influence patient satisfaction. Most scholars have focused primarily on patient and institutional characteristics. The patient characteristics in their works have included demographic information, such as gender, ${ }^{9,11,12}$ age, ${ }^{9,12-14}$ marital status, ${ }^{12}$ education, ${ }^{15}$ family income, ${ }^{9,16}$ and residence, ${ }^{12}$ as well as medical information, such as the type of insurance coverage ${ }^{9,14}$ and self-reported health status. $^{13,15,17}$ Institutional characteristics have included information on the type of medical facility, ${ }^{9}$ location, ${ }^{11}$ number of beds, and staffing. ${ }^{9,18}$ However, rarely has any individual study addressed both patient and institutional characteristics. This study was designed to provide a more comprehensive understanding of satisfaction through the integration of both types of factors into the analysis.

We collected data on four domains of patient satisfaction as well as overall satisfaction with hospitals. We used a multivariate logistic regression model to explore the influence of patient and institutional characteristics on inpatient satisfaction. We identified both the key factors that influenced inpatients' satisfaction as well as the implications that could inform policy efforts designed to assure the quality improvement of district-level hospitals.

\section{Patients and Methods}

\section{Survey Instrument}

In 2019, the team, comprised of researchers from Peking Union Medical College (PUMC) School of Public Health, conducted a survey of inpatient satisfaction in Beijing's district-level hospitals. The survey instrument was designed based on relevant patient survey scales, including the Service Quality Model (also known as SERVQUAL Model), ${ }^{8,19-21}$ and was validated by consultations with multidisciplinary experts and a small-scale pilot survey. Patient satisfaction was measured by 12 items over 4 domains: administrative processes, hospital environment, medical care, hospitalization expenses, plus overall satisfaction. Responses for 13 items were scored on a 5-point Likert scale: 5 (Very satisfied), 4 (Satisfied), 3 (Moderate), 2 (Unsatisfied), or 1 (Completely dissatisfied). For each domain, Cronbach's $\alpha$ was calculated to evaluate internal consistency (Table 1).

In addition to satisfaction domains, the questionnaire included patient sociodemographic information such as gender, age, education, and income, as well as healthcarerelated information, such as the type of medical insurance, self-reported health status, and the presence or absence of chronic disease. Information on the institutional characteristics of hospitals, such as the type of hospital, location, and grade (secondary or tertiary), were collected from facilities' official websites and the National Health Commission of China (NHCC). The location of hospitals was defined as either urban or rural according to whether the hospital is located in urban or suburban districts of Beijing, because suburban hospitals serve a large rural population. Information on grade included hospital size and medical specialties. Tertiary hospitals usually have over 500 beds and provided high-level specialist medical services to patients. Therefore, hospital grade could represent both size and the technical quality of a hospital. Questionnaire for this survey is presented in Appendix 1.

\section{Setting and Participants}

We conducted the survey in 47 district-level hospitals in Beijing from May to June 2019. All of the 16 districts in Beijing were included. We selected 1 district-level general hospital, 1 district-level Traditional Chinese Medicine hospital (TCM), and 1 district-level maternal and child health hospital $(\mathrm{MCH})$ from each district. While one maternal and child health hospital was excluded because there were no inpatients. We supposed that $60 \%$ inpatients were satisfied with the hospital service, set the significant level at 0.05 , permissible error at $3 \%$. We calculated the minimum sample size which is 1024 . For each hospital, 30 inpatients aged 18 and over who would be discharged on the survey day or the following day were sampled in each hospital.

\section{Data Collection}

The trained investigators randomly selected participants from lists of inpatients about to be discharged in each hospital with a random number table and asked the patients to complete the electronic questionnaires online. If the patient could not complete the questionnaire because 
Table I Inpatient Satisfaction, Internal Consistency, and Average Domain Scores

\begin{tabular}{|c|c|c|c|c|}
\hline Domain & Items & Questions & Cronbach's $\alpha$ & $\begin{array}{l}\text { Average Scores } \\
\text { (SD) }\end{array}$ \\
\hline $\begin{array}{l}\text { Administrative } \\
\text { processes }\end{array}$ & 2 & $\begin{array}{l}\text {-I am satisfied with the waiting time for admission } \\
\text {-I am satisfied with the admission procedure }\end{array}$ & 0.744 & $4.37(0.59)$ \\
\hline Hospital environment & 4 & $\begin{array}{l}\text {-I am satisfied with the quietness of the ward } \\
\text {-I am satisfied with the cleanness and absence of smells in ward and } \\
\text { toilet } \\
- \text { I am satisfied with the quality of meals } \\
- \text { I am satisfied with the signage in the hospital }\end{array}$ & 0.752 & $4.00(0.59)$ \\
\hline Medical care & 5 & $\begin{array}{l}\text {-I am satisfied with the skills of the attending physician } \\
-I \text { am satisfied with the physician in charge of my bed } \\
-I \text { am satisfied with the nurses' care } \\
\text {-I am satisfied with the protection of patient's privacy by medical } \\
\text { staff } \\
-I \text { am satisfied with treatment outcomes }\end{array}$ & 0.870 & $4.44(0.47)$ \\
\hline $\begin{array}{l}\text { Hospitalization } \\
\text { expenses }\end{array}$ & $\mathrm{I}$ & $-I$ am satisfied with hospitalization expenses & - & $3.89(0.78)$ \\
\hline Overall satisfaction & I & -Overall, I am satisfied with this hospitalization & - & $4.33(0.61)$ \\
\hline
\end{tabular}

Notes: For domain of "Hospitalization expenses" or "Overall satisfaction", there was only one item, so no Cronbach's $\alpha$ was calculated. These two blanks were filled with "-".

they were illiterate or unable to read, the investigators would go over each question with the patient and record the responses online. Patients who were below 18, unable to administer the questionnaire or unwilling to participate were excluded. All respondents signed informed consent forms.

\section{Statistics Analysis}

We calculated the average score of items for each domain and tested the internal consistency using Cronbach's $\alpha$ coefficient. To make a preliminary identification of the relationship between patient and institutional characteristics and patient satisfaction, the Kruskal-Wallis $H$-test and the Mann-Whitney $U$-test were used to compare the scores for each domain, with $\alpha=0.05$.

Multivariate binary logistic regression was used to identify key factors related to overall inpatient satisfaction and satisfaction for each domain. We transferred the dependent variables into a binary variable at a cutoff point of 4 (Satisfaction=0 if the average score for the domain is below 4 and Satisfaction=1 if average score for the domain is 4 or above). Then we used a forward stepwise method, using the criteria of $P<0.05$ for inclusion and $P>0.10$ for exclusion. All of the statistics were performed using IBM SPSS Statistics 24.0 software.

\section{Results}

\section{Descriptive Statistics}

The Cronbach's $\alpha$ of each domain is from 0.744 to 0.870 , as shown in Table 1, indicating good internal consistency within each domain. A total of 1517 patients participated in the survey among which there were 1458 effective questionnaires (96.1\% effective rate). Of the 1458 participants, 577 (39.6\%) were men, 581 (39.8\%) were over 60 years of age, and $824(56.5 \%)$ had at least a high school education. The monthly family income (MFI) of 584 (40.1\%) of the participants was less than 5000 yuan, of $549(37.7 \%)$ of them was between 5000 and 10,000 yuan, and of the remaining 325 $(22.3 \%)$ was 10,000 yuan or more. Only $134(9.2 \%)$ of the participants had Government Insurance Scheme (GIS), 540 (37.0\%) had Urban Employees Basic Medical Insurance (UEBMI), 670 (46.0\%) had Urban and Rural Residents Basic Medical Insurance (URBMI), and 114 (7.8\%) had other medical insurance or no insurance. Less than a quarter of the participants $(22.3 \%$ ) reported that their health was better than their peers and $396(27.2 \%)$ reported that their health was poorer than that of their peers. More than half of the participants $(52.8 \%)$ reported they had at least one chronic disease. Table 2 illustrates these findings.

There were 16 general hospitals with 541 (37.1\%) participants, 16 Traditional Chinese Medicine hospitals 
Table 2 Patient Characteristics and the Average Scores of Satisfaction in Five Domains $(\mathrm{N}=1458)$

\begin{tabular}{|c|c|c|c|c|c|c|}
\hline Specification & $\begin{array}{c}\text { Number of } \\
\text { Inpatients } \mathbf{N}(\%)\end{array}$ & $\begin{array}{c}\text { Administrative } \\
\text { Processes }\end{array}$ & $\begin{array}{c}\text { Hospital } \\
\text { Environment }\end{array}$ & $\begin{array}{c}\text { Medical } \\
\text { Care }\end{array}$ & $\begin{array}{c}\text { Hospitalization } \\
\text { Expenses }\end{array}$ & $\begin{array}{c}\text { Overall } \\
\text { Satisfaction }\end{array}$ \\
\hline Total & $1458(100 \%)$ & 4.37 & 4.00 & 4.44 & 3.89 & 4.33 \\
\hline \multicolumn{7}{|l|}{ Gender } \\
\hline Male & $577(39.6 \%)$ & 4.36 & 4.01 & 4.44 & 3.84 & 4.34 \\
\hline Female & $881(60.4 \%)$ & 4.39 & 4.00 & 4.44 & 3.92 & 4.32 \\
\hline$P$ & & 0.69 & 0.72 & 0.70 & 0.04 & 0.63 \\
\hline \multicolumn{7}{|l|}{ Age } \\
\hline $18-60$ & $877(60.2 \%)$ & 4.39 & 4.02 & 4.46 & 4.05 & 4.28 \\
\hline$>60$ & $58 I(39.8 \%)$ & 4.36 & 3.97 & 4.46 & 3.81 & 4.36 \\
\hline$P$ & & 0.34 & 0.08 & 0.20 & 0.002 & 0.30 \\
\hline \multicolumn{7}{|l|}{$\begin{array}{l}\text { Family income } \\
\text { monthly }\end{array}$} \\
\hline$<5000$ & $584(40.1 \%)$ & 4.36 & 3.99 & 4.42 & 3.73 & 4.34 \\
\hline $5000-10,000$ & $549(37.7 \%)$ & 4.39 & 4.03 & 4.46 & 3.96 & 4.34 \\
\hline$\geq 10,000$ & $325(22.3 \%)$ & 4.38 & 3.98 & 4.44 & 4.05 & 4.30 \\
\hline$P$ & & 0.50 & 0.32 & 0.17 & $<0.001$ & 0.84 \\
\hline \multicolumn{7}{|l|}{ Education } \\
\hline $\begin{array}{l}\text { High school or } \\
\text { above }\end{array}$ & $824(56.5 \%)$ & $4.4 I$ & 4.02 & 4.46 & 4.00 & 4.33 \\
\hline $\begin{array}{l}\text { Middle school or } \\
\text { below }\end{array}$ & $634(43.5 \%)$ & 4.34 & 3.98 & 4.41 & 3.75 & 4.33 \\
\hline$P$ & & 0.008 & 0.18 & 0.04 & $<0.001$ & 0.67 \\
\hline \multicolumn{7}{|l|}{ Medical insurance } \\
\hline GIS & $134(9.2 \%)$ & 4.45 & 4.06 & 4.50 & 4.11 & 4.45 \\
\hline UEBMI & $540(37.0 \%)$ & 4.44 & 4.01 & 4.47 & 3.99 & 4.34 \\
\hline URBMI & $670(46.0 \%)$ & 4.33 & 3.99 & 4.41 & 3.75 & 4.31 \\
\hline Others & $114(7.8 \%)$ & 4.29 & 3.98 & 4.37 & 3.92 & 4.25 \\
\hline$P$ & & 0.002 & 0.46 & 0.12 & $<0.001$ & 0.03 \\
\hline \multicolumn{7}{|l|}{$\begin{array}{l}\text { Self-reported health } \\
\text { status }\end{array}$} \\
\hline Better than peers & $325(22.3 \%)$ & 4.45 & 4.05 & 4.47 & 3.96 & 4.36 \\
\hline Same as peers & $737(50.5 \%)$ & 4.37 & 4.02 & 4.45 & 3.92 & 4.31 \\
\hline Poorer than peers & $396(27.2 \%)$ & 4.34 & 3.93 & 4.40 & 3.78 & 4.34 \\
\hline$P$ & & 0.02 & 0.005 & 0.18 & 0.004 & 0.32 \\
\hline \multicolumn{7}{|l|}{ Chronic disease } \\
\hline No CD & $688(47.2 \%)$ & 4.38 & 4.02 & 4.45 & 3.97 & 4.32 \\
\hline At least a $C D$ & $770(52.8 \%)$ & 4.37 & 3.98 & 4.43 & 3.82 & 4.34 \\
\hline$P$ & & 0.41 & 0.10 & 0.46 & $<0.001$ & 0.60 \\
\hline
\end{tabular}

Notes: Bold $P$ values $<0.05$.

Abbreviations: GIS, Government Insurance Scheme; UEBMI, Urban Employees Basic Medical Insurance; URBMI, Urban and Rural Residents Basic Medical Insurance; Others include commercial insurance, medical aid, and no medical insurance; $C D$, chronic disease.

(TCMs) with $536(36.8 \%)$ participants, and 15 maternal and child health hospitals (MCHs) with 381 (26.1\%) participants. A total of 17 hospitals were in urban areas with $528(36.2 \%)$ participants and 30 hospitals were in suburbs with $930(63.8 \%)$ participants. There were 19 tertiary hospitals with $642(44.0 \%)$ participants and 28 secondary hospitals with 816 (56.0\%) participants (Table 3).

The average satisfaction scores for administrative processes, hospital environment, medical care, hospitalization expenses, and overall satisfaction were 4.37, 4.00, 4.44, 
Table 3 Institutional Characteristics and Satisfaction Scores in Five Domains $(N=1458)$

\begin{tabular}{|c|c|c|c|c|c|c|c|}
\hline Specification & $\begin{array}{l}\text { Number of } \\
\text { Hospitals }\end{array}$ & $\begin{array}{c}\text { Number of } \\
\text { Inpatients N (\%) }\end{array}$ & $\begin{array}{l}\text { Administrative } \\
\text { Processes }\end{array}$ & $\begin{array}{c}\text { Hospital } \\
\text { Environment }\end{array}$ & $\begin{array}{l}\text { Medical } \\
\text { Care }\end{array}$ & $\begin{array}{l}\text { Hospitalization } \\
\text { Expenses }\end{array}$ & $\begin{array}{c}\text { Overall } \\
\text { Satisfaction }\end{array}$ \\
\hline Total & 47 & $1458(100 \%)$ & 4.37 & 4.00 & 4.44 & 3.89 & 4.33 \\
\hline \multicolumn{8}{|l|}{ Hospital type } \\
\hline $\mathrm{GH}$ & 16 & $54 I(37.1 \%)$ & 4.36 & 4.08 & 4.45 & 3.82 & 4.38 \\
\hline TCM & 16 & $536(36.8 \%)$ & 4.40 & 3.96 & 4.46 & 3.90 & 4.36 \\
\hline $\mathrm{MCH}$ & 15 & $381(26.1 \%)$ & 4.35 & 3.95 & 4.39 & 3.98 & 4.22 \\
\hline$P$ & & & 0.54 & $<0.001$ & 0.06 & 0.008 & 0.001 \\
\hline \multicolumn{8}{|l|}{$\begin{array}{l}\text { Hospital } \\
\text { location }\end{array}$} \\
\hline Urban & 17 & $528(36.2 \%)$ & 4.47 & 4.07 & 4.50 & 4.04 & 4.41 \\
\hline Suburban & 30 & $930(63.8 \%)$ & 4.33 & 3.96 & 4.40 & 3.80 & 4.29 \\
\hline$P$ & & & $<0.001$ & 0.001 & $<0.001$ & $<0.001$ & $<0.001$ \\
\hline \multicolumn{8}{|l|}{ Hospital grade } \\
\hline Secondary & 28 & $816(56.0 \%)$ & 4.36 & 3.98 & 4.41 & 3.90 & 4.29 \\
\hline Tertiary & 19 & $642(44.0 \%)$ & 4.39 & 4.03 & 4.48 & 3.87 & 4.38 \\
\hline$P$ & & & 0.52 & 0.09 & 0.02 & 0.69 & 0.01 \\
\hline
\end{tabular}

Notes: Mann-Whitney $U$ and Kruskal-Wallis $H$-tests were used to compare the difference in satisfaction scores between groups. Bold $P$ values $<0.05$. Abbreviations: GH, general hospital; TCM, Traditional Chinese Medicine hospital; MCH, maternal and child health hospital.

3.89 , and 4.33 , respectively. The levels of satisfaction regarding the hospital environment and hospitalization expenses were relatively low. However, the levels of satisfaction with the medical care received and administrative processes were relatively high. The overall satisfaction level was in the middle.

\section{Patient Characteristics and Inpatient Satisfaction}

Table 2 illustrates the correlation between patient characteristics and satisfaction scores. The Mann-Whitney U and Kruskal-Wallis $H$-tests showed that patient satisfaction with regard to hospitalization expenses varied significantly according to gender, age, and income groups. Female inpatients, inpatients between the ages of 18 and 60, and those from families with higher incomes tended to be more satisfied with hospitalization expenses. Inpatients with higher educational levels had higher patient satisfaction scores for administrative process, medical care, and hospitalization expenses. Participants with different types of insurance demonstrated different levels of patient satisfaction with administrative process, hospitalization expenses, and overall satisfaction. Inpatients with GIS had the highest scores. Patients with low scores on self-reported health also had low scores on satisfaction with administrative process, hospital environment, and hospitalization expenses. Inpatients with at least one chronic disease demonstrated lower levels of patient satisfaction with hospitalization expenses than those without any chronic conditions.

\section{Institutional Characteristics and Inpatient Satisfaction}

The Mann-Whitney $\mathrm{U}$ and the Kruskal-Wallis $H$-tests revealed a significant difference across hospital types in terms of inpatient satisfaction with hospital environment, hospitalization expenses, and overall satisfaction. General hospitals received the highest satisfaction scores on hospital environment and overall satisfaction. MCHs had the lowest satisfaction scores on hospital environment and overall satisfaction, but the highest satisfaction scores on hospitalization expenses. Hospital location also proved important; urban hospitals earned higher scores than suburban hospitals across all of the domains. Hospital of different grades varied with regard to medical care and overall satisfaction. Tertiary hospitals scored higher than secondary hospitals (Table 3 ).

\section{Logistic Regression Results of Hospital and Inpatient Characteristics}

We found that different hospital types showed significant associations with inpatient satisfaction across all of the 
regression models (Table 4). The hospital type was the only factor that showed significance for overall satisfaction. Inpatients receiving care in MCHs were 51\% less likely to be satisfied than those in general hospitals $(O R=$ $0.49,95 \%$ CI $[0.30,0.80])$. Additionally, hospital type also was the only significant variable with regard to level of satisfaction with medical care. The patients receiving care in TCMs were 2.07 times more likely to be satisfied with medical care compared to general hospitals $(O R=2.07$, 95\% CI [1.24, 3.47]).

Hospital type and education proved to be significant factors in the level of satisfaction with administrative process. Those receiving care in $\mathrm{MCHs}$ were $92 \%$ less likely to be satisfied compared to those in general hospitals $(O R=0.08,95 \% C \mathrm{I}[0.05,0.11])$. The patients with only middle school education or lower were 2.11 times more likely to be satisfied than those with a high school education or higher $(O R=2.11,95 \%$ CI [1.49, 2.97]). The factors that influenced the levels of satisfaction with the hospital environment were hospital type, hospital location, age, and self-reported health status. Those receiving care in MCHs and TCMs were 47\% and 30\% less likely to be satisfied with environment, respectively $(O R=0.53,95 \%$ $C I[0.39,0.72]$ and $O R=0.70,95 \% C I[0.55,0.90]$, respectively). Inpatients in suburban hospitals, over 60 years of age and poorer health status were $21 \%, 25 \%$ and $37 \%$ less likely to be satisfied with hospital environment, respectively $(O R=0.79,95 \% C I[0.63,0.98], \mathrm{OR}=$ $0.75,95 \% C I[0.59,0.96]$ and $O R=0.63,95 \% C I[0.48$, $0.82]$, respectively).

The hospital type and location, as well as patient gender, monthly family income, and type of medical insurance all proved to be significant variables with regard to satisfaction with hospitalization expenses. Inpatients receiving care in TCMs were 1.46 times more likely to be satisfied compared to those in general hospitals $(O R=1.46,95 \% C I$ $[1.11,1.92])$. Inpatients in suburban hospitals were $36 \%$ less likely to be satisfied compared to their counterparts in urban hospitals than their counterparts in urban hospitals $(O R=0.64,95 \%$ CI $[0.49,0.84])$. Female patients were more satisfied compared to males $(O R=1.41,95 \% C I$ $[1.08,1.84])$. Higher income was associated with higher satisfaction with hospitalization expenses. Patients with MFI between 5000 and 10,000 yuan and those with over 10,000 yuan were 1.51 times and 1.71 times more likely to be satisfied with hospitalization expenses than those with MFI below 5000 yuan respectively. Inpatients with GIS and UEBMI were 2.30 times and 1.40 times more likely to be satisfied with expenses than those with URBMI. Hospital grade and chronic disease were not included in all of the multivariate regressions (Table 4).

\section{Discussion}

Our study assessed the level of inpatient satisfaction overall as well as for four distinct domains. We found that the inpatient satisfaction scores for hospital environment and hospitalization expenses were lower, whereas those on medical care and administrative processes were higher. The overall satisfaction score was just in the middle. This finding was stable across different hospital types, locations, and grades. Moreover, overall satisfaction reflected the comprehensive experiences of patients. Therefore, an examination of the distinct domains of experience proved useful. The district hospitals' environments were not satisfying. Hospital ward infrastructure, quietness, and cleanliness all could be improved. The satisfaction scores for district-level hospitals in Beijing occupied the middle range of those for other hospitals in China. A national patient survey across 136 tertiary hospitals in 2017 received overall satisfaction scores of 4.6 4.7 for inpatients, compared to an average score of 4.33 in this study. Another study of inpatients of countylevel hospitals in 11 western provinces in China revealed an overall satisfaction score of 3.80. ${ }^{9,22}$

The dissatisfaction with the expense of hospitalization has continued in China due to both inadequate medical insurance coverage and the amount needed to cover medical costs compared to average earnings for Chinese patients. An article published in the Lancet in 2014 emphasized that increases in out-of-pocket health-care expenses represented a major cause of patient dissatisfaction. ${ }^{23}$ Although the reimbursement rate provided by social health insurance coverage has increased over the years and the disparities among different insurance plans have shrunk, out-of-pocket expenses continue to represent a significant concern for patients. Our results were consistent with findings from recent studies. ${ }^{24,25}$ The 5th National Health Service Survey in China revealed that residents expressed the lowest levels of satisfaction with hospital environment and hospitalization expenses for participants who had been hospitalized during the past year. ${ }^{24}$ A large-scale cross-sectional study of inpatient satisfaction in the central south area of China found that people also were the least satisfied with the hospital environment and expenses. $^{25}$ To improve patient satisfaction with regard to medical expenses, policies that would curb unreasonable 


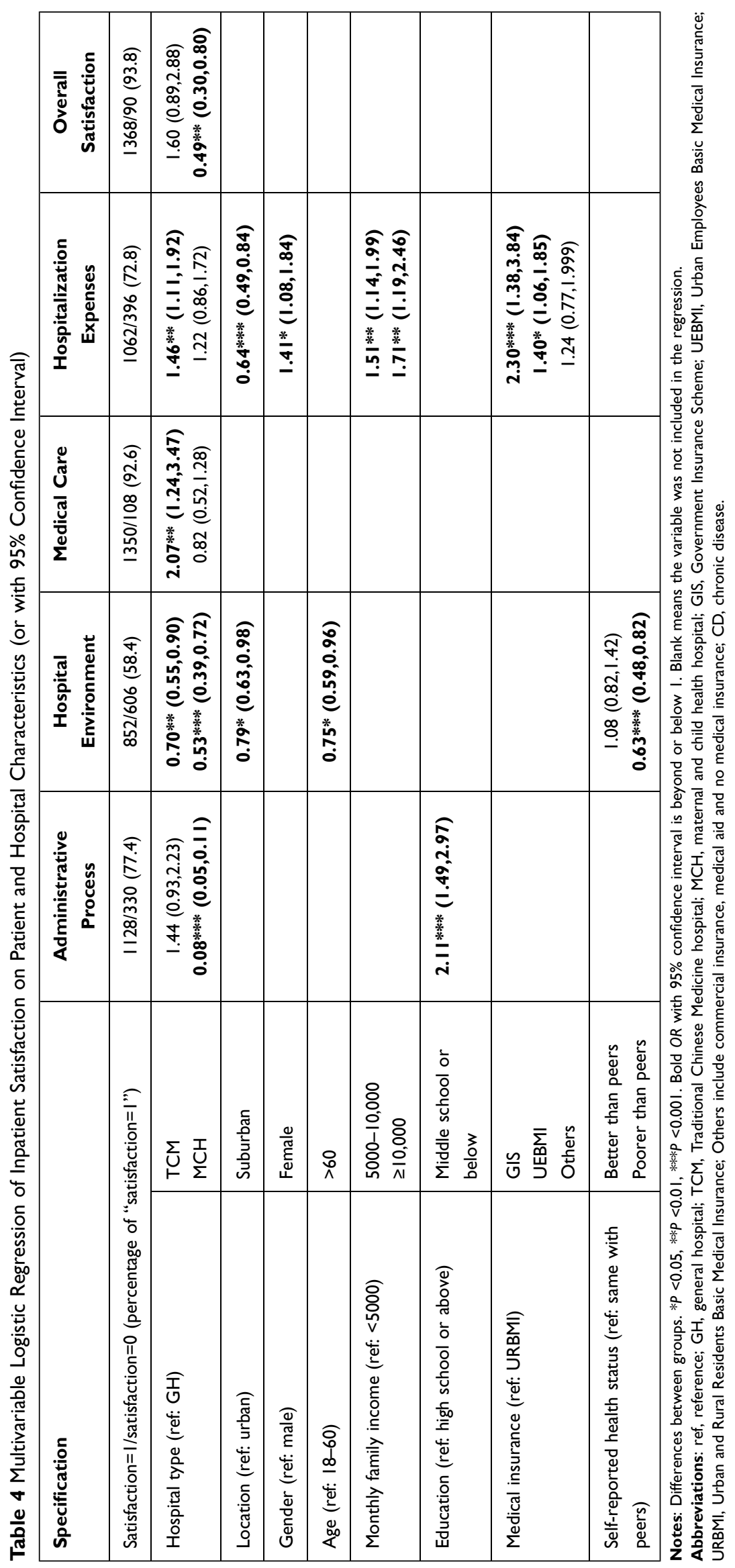


cost increases coupled with an expansion of medical insurance benefits are needed.

In this study, multivariate logistic regressions were used to analyze the factors that influenced inpatient satisfaction. Gender proved to be an important factor for inpatient satisfaction with hospitalization expenses and female patients had higher scores. Additionally, inpatients with higher family incomes and those holding GIS and UEBMI insurance were more satisfied with hospital expenses. A consolidation of the different medical insurance plans would help to improve inpatients' satisfaction with expenses, a suggestion that also has appeared in other studies. $^{23,26}$ Inpatients with lower education exhibited higher satisfaction with administrative process. This result proved consistent with most previous studies that also documented a negative association between education and inpatient satisfaction. ${ }^{27-29}$ Some scholars in the field of psychology have claimed that patients with lower levels of education exhibited greater trust, held lower expectations, had higher satisfaction and submitted fewer medical claims than those with higher levels of education. ${ }^{30}$ After controlling for other patient and institutional factors, this research also arrived at the same conclusion.

Most studies that explored the relationship between age and patient satisfaction and yielded a variety of different results. ${ }^{3,5-7,16}$ We found that elderly inpatients ( $>60$ years of age) were less satisfied with hospitalization expenses. However, the difference was not significant in the final model. Generally elderly inpatients had poorer health, which led to longer hospital stays and higher expenses. ${ }^{15}$ Moreover, elderly patients had lower incomes, which could have made them more sensitive to expenses. However, this association could be weakened through the inclusion of adding income and self-reported health variables in the regression. Additionally, we found that elderly inpatients ( $>60$ years of age) were less satisfied with the hospital environment. This could have been related to the elderly inpatients' vulnerable physical conditions, which would contribute to higher expectations with regard to facilities and patient-friendly environment.

Patient's self-reported health status was a key index for adjusting patient satisfaction. ${ }^{17}$ Multivariate regression showed that inpatients with poorer self-reported health status had significantly lower satisfaction with the hospital environment. Previous studies also revealed that patients with chronic conditions had lower satisfaction. ${ }^{27,31-34}$ The association between chronic disease and inpatient satisfaction was significant in the univariate analysis over several domains. However, it did not prove statistically significant in the final regression. This was probably due to the confounding effect of self-reported health status.

Previous studies found that patient satisfaction varied across different hospital types, locations, and grades. ${ }^{11,35}$ Compared to inpatients in general hospitals, those in MCHs were significantly less satisfied with administrative process $(O R=0.08)$, hospital environment $(O R=0.53)$. Moreover, they exhibited lower scores on overall satisfaction $(O R=0.49)$. MCHs primarily have served women during pregnancy and childbirth in the districts. Owing to the "two children" fertility policy change in China, there has been a high volume of delivery patients and MCHs increasingly have become crowded. The discomfort and anxiety that often accompany pregnancy and childbirth have contributed to patients' desire for streamlined processes and comfortable surroundings. ${ }^{36}$ These expectations could explain why MCHs had worse scores across several domains. Compared to general hospitals, TCMs scored higher on medical care service and expenses, but lower on hospital environment. Medical personnel at TCMs usually perform noninvasive procedures. They also tend to be patient with inpatients. However, there still is a need for improvement in the hospital environment of TCMs.

The inpatients at suburban hospitals were significantly less satisfied with the hospital environment and hospitalization expenses than those at urban hospitals. This could be explained by the poor infrastructure at suburban hospitals. Additionally, suburban inpatients were of a lower social economic status, had worse medical insurance, and struggled more with the cost of healthcare than their urban counterparts. ${ }^{26}$ With regard to hospital grade, the tertiary hospitals received higher scores related to hospital environment, medical care, and overall satisfaction. However, the multivariate analyses revealed that the difference was not statistically significant after controlling for inpatient characteristics. This finding reaffirms the need to include patient characteristics in any comparative analysis of patient satisfaction among different hospitals.

The findings from this research have some important implications. First, an evaluation of overall satisfaction with a single item question would yield mixed results across different domains. In this study, the overall satisfaction score was in the middle of four domains. Moreover, few factors were significantly associated with overall satisfaction in the multivariate regression. However, an analysis of the different domains yielded a number of associations between satisfaction and patient-level as well as hospital-level 
characteristics. Therefore, it would prove useful to separate patient satisfaction into discrete domains and explore the factors that influence each one. Second, patients' sociodemographic characteristics significantly affected their experiences in hospitals. Therefore, it would be necessary to account for the composition of patients in any evaluation of patient satisfaction across hospitals. Third, the inpatients included were those discharged on the same day or the day following the administration of the questionnaire. Because they had just completed the entire process of hospitalization, there was a reduced risk of recall bias.

This study had some limitations. First, the sample hospitals are all district-level hospitals of Beijing. Therefore, the results did not represent the overall situation of inpatient satisfaction with medical services in mid-level medical institutions in China. Second, the survey was conducted onsite in the wards before the patient is discharged. Although the medical staff were requested not to be present while the surveys were in progress, it was still possible that the patient gave higher ratings before they left the hospital. This could have resulted in biased (usually higher) satisfaction scores.

\section{Conclusion}

This study explored the level of satisfaction as well as the factors that influenced inpatient satisfaction in Beijing's district-level hospitals. Among the 4 domains, the level of satisfaction with hospitalization expenses and hospital environment were relatively lower. Comparison between different types of hospitals revealed that the level of satisfaction with maternal and child health hospitals and suburban hospitals were lower, and such gaps should be addressed in the future. Additionally, the association between hospital and individual-level characteristics and satisfaction varied across various domains, indicating the necessity of disentangling the different determinants of satisfaction over individual domains in hospital evaluation.

These new evidences could inform the development of targeted policies and interventions designed to enhance the medical services provided by district-level hospitals in China. Further study could explore additional institutional characteristics and their effects on satisfaction in districtlevel hospitals.

\section{Data Sharing Statement}

The datasets used and/or analyzed during the current study are available from the corresponding author on reasonable request.

\section{Ethics Approval and Consent to Participate}

The protocol for this study was approved by the Ethics Committee of PUMC (SPH201712CHII206). The patient satisfaction survey was anonymous. We obtained written informed consent from each respondent before their participation in the survey. This study was conducted in accordance with the Declaration of Helsinki.

\section{Acknowledgments}

We appreciate Beijing Municipal Health Commission, who provided strong support to the survey. We also appreciate 16 district health authorities in coordination with sample hospitals. We thank LetPub (www.letpub.com) for its linguistic assistance during the preparation of this manuscript.

\section{Funding}

This work was supported by the Chinese Academy of Medical Sciences under Grant 2017-I2M-B\&R-17 and 2020-I2M-2-016.

\section{Disclosure}

The authors report no conflicts of interest in this work.

\section{References}

1. Hamka SW. Effect of service quality and customer satisfaction patients in general hospitals of Makassar City Region. $J$ Physics. 2018;1028:012107.

2. Al-Abri R, Al-Balushi A. Patient satisfaction survey as a tool towards quality improvement. Oman Med J. 2014;29(1):3-7. doi:10.5001/ omj.2014.02

3. Manary MP, Boulding W, Staelin R, Glickman SW. The patient experience and health outcomes. $N$ Engl J Med. 2013;368 (3):201-203. doi:10.1056/NEJMp1211775

4. Garcia-Gutierrez S, Quintana JM, Aguire U, et al. Impact of clinical and patient-reported outcomes on patient satisfaction with cataract extraction. Health Expect. 2014;17(6):765-775. doi:10.1111/j.13697625.2012.00801.x

5. Yin T, Yin DL, Xiao F, et al. Socioeconomic status moderates the association between patient satisfaction with community health service and self-management behaviors in patients with type 2 diabetes: a cross-sectional survey in China. Medicine (Baltimore). 2019;98(22): e15849. doi:10.1097/MD.0000000000015849

6. Li J, Wang P, Kong X, Liang H, Zhang X, Shi L. Patient satisfaction between primary care providers and hospitals: a cross-sectional survey in Jilin province, China. Int J Qual Health Care. 2016;28(3):346-354. doi:10.1093/intqhe/mzw038

7. Dong W, Zhang Q, Yan C, Fu W, Xu L. Residents' satisfaction with primary medical and health services in Western China. BMC Health Serv Res. 2017;17(1):298. doi:10.1186/s12913-017-2200-9

8. Sun J, Hu G, Ma J, et al. Consumer satisfaction with tertiary healthcare in China: findings from the 2015 China National Patient Survey. Int J Qual Health Care. 2017;29(2):213-221. doi:10.1093/intqhe/ mzw160 
9. Hu L, Ding H, Liu S, et al. Influence of patient and hospital characteristics on inpatient satisfaction in China's tertiary hospitals: a cross-sectional study. Health Expect. 2020;23(1):115-124. doi:10.1111/hex.12974

10. Graham B. Defining and measuring patient satisfaction. J Hand Surg Am. 2016;41(9):929-931. doi:10.1016/j.jhsa.2016.07.109

11. Liew H, Brooks T. A conjoint analysis of inpatient satisfaction ratings in Indonesia. Health Policy Technol. 2016;6.

12. Chen H, Li M, Wang J, et al. Factors influencing inpatients' satisfaction with hospitalization service in public hospitals in Shanghai, People's Republic of China. Patient Prefer Adherence. 2016;10:469-477. doi:10.2147/PPA.S98095

13. Mitropoulos P, Vasileiou K, Mitropoulos I. Understanding quality and satisfaction in public hospital services: a nationwide inpatient survey in Greece. J Retail Consum Serv. 2018;40:270-275. doi:10.1016/j. jretconser.2017.03.004

14. Shan L, Li Y, Ding D, et al. Patient satisfaction with hospital inpatient care: effects of trust, medical insurance and perceived quality of care. PLoS One. 2016;11(10):e0164366. doi:10.1371/journal. pone.0164366

15. Chumbler NR, Otani K, Desai SP, et al. Hospitalized older adults' patient satisfaction: inpatient care experiences. SAGE Open. 2016;6 (2):2158244016645639. doi:10.1177/2158244016645639

16. Peres-da-silva A, Kleeman LT, Wellman SS, et al. What factors drive inpatient satisfaction after knee arthroplasty? J Arthroplasty. 2017;32 (6):1769-1772. doi:10.1016/j.arth.2017.01.036

17. Hekkert KD, Cihangir S, Kleefstra SM, et al. Patient satisfaction revisited: a multilevel approach. Soc Sci Med. 2009;69(1):68-75. doi:10.1016/j.socscimed.2009.04.016

18. Victoor A, Delnoij DM, Friele RD, et al. Determinants of patient choice of healthcare providers: a scoping review. BMC Health Serv Res. 2012;12:272. doi:10.1186/1472-6963-12-272

19. Talib F, Azam M, Rahman Z. Service quality in healthcare establishments: a literature review. Int J Behav Healthc Res. 2015;5:1-24. doi:10.1504/IJBHR.2015.071465

20. Camgöz-Akdag H, Zineldin M, Sinha M. Quality of health care and patient satisfaction: an exploratory investigation of the 5Qs model at Turkey. Clin Govern. 2010;15:92-101. doi:10.1108/ 14777271011035031

21. Aagja JP, Garg R. Measuring perceived service quality for public hospitals (PubHosQual) in the Indian context. Int J Pharm Healthc Market. 2010;4(1):60-83. doi:10.1108/17506121011036033

22. Liu J, Mao Y. Patient satisfaction with rural medical services: a cross-sectional survey in 11 western provinces in China. Int J Environ Res Public Health. 2019;16(20):3968. doi:10.3390/ ijerph16203968

23. Xu W. Violence against doctors in China. Lancet. 2014;384 (9945):745. doi:10.1016/S0140-6736(14)61438-0
24. Ling XU, Meng Q. Patient satisfation from the fifth national health service survey. Chin J Health Inform Manag. 2014;11(02):104-105. in Chinese.

25. Wei J, Wang XL, Yang HB, Yang TB, Manzoli L. Development of an in-patient satisfaction questionnaire for the Chinese population. PLoS One. 2015;10(12):e0144785. doi:10.1371/journal.pone.0144785

26. Xian W, Xu X, Li J, et al. Health care inequality under different medical insurance schemes in a socioeconomically underdeveloped region of China: a propensity score matching analysis. BMC Public Health. 2019;19(1):1373. doi:10.1186/s12889-019-7761-6

27. Baummer-Carr A, Nicolau DP. The challenges of patient satisfaction: influencing factors and the patient - provider relationship in the United States. Expert Rev Anti Infect Ther. 2017;15(10):955-962. doi:10.1080/14787210.2017.1378097

28. Koné Péfoyo AJ, Wodchis WP. Organizational performance impacting patient satisfaction in Ontario hospitals: a multilevel analysis. BMC Res Notes. 2013;6:509. doi:10.1186/1756-0500-6-509

29. Carlin CS, Christianson JB, Keenan P, et al. Chronic illness and patient satisfaction. Health Serv Res. 2012;47(6):2250-2272. doi:10.1111/j.1475-6773.2012.01412.x

30. Bjertnaes OA, Sjetne IS, Iversen HH. Overall patient satisfaction with hospitals: effects of patient-reported experiences and fulfilment of expectations. BMJ Qual Saf. 2012;21(1):39-46. doi:10.1136/ bmjqs-2011-000137

31. Hawthorne G, Sansoni J, Hayes L, Marosszeky N, Sansoni E. Measuring patient satisfaction with health care treatment using the short assessment of patient satisfaction measure delivered superior and robust satisfaction estimates. J Clin Epidemiol. 2014;67 (5):527-537. doi:10.1016/j.jclinepi.2013.12.010

32. Rahmqvist M, Bara AC. Patient characteristics and quality dimensions related to patient satisfaction. Int J Qual Health Care. 2010;22 (2):86-92. doi:10.1093/intqhe/mzq009

33. Schoenfelder T, Klewer J, Kugler J. Determinants of patient satisfaction: a study among 39 hospitals in an in-patient setting in Germany. Int J Qual Health Care. 2011;23(5):503-509. doi:10.1093/intqhe/ mzr038

34. Mukasa JP, Glass N, Mnatzaganian G. Ethnicity and patient satisfaction with tuberculosis care: a cross-sectional study. Nurs Health Sci. 2015;17(3):395-401. doi:10.1111/nhs.12202

35. Kraska RA, Weigand M, Geraedts M. Associations between hospital characteristics and patient satisfaction in Germany. Health Expect. 2017;20(4):593-600. doi:10.1111/hex.12485

36. Srivastava A, Avan BI, Rajbangshi P, et al. Determinants of women's satisfaction with maternal health care: a review of literature from developing countries. BMC Pregnancy Childbirth. 2015;15:97. doi:10.1186/s12884-015-0525-0
Patient Preference and Adherence

\section{Publish your work in this journal}

Patient Preference and Adherence is an international, peer-reviewed, open access journal that focusing on the growing importance of patient preference and adherence throughout the therapeutic continuum. Patient satisfaction, acceptability, quality of life, compliance, persistence and their role in developing new therapeutic modalities and compounds to optimize clinical outcomes for existing disease states are major areas of interest for the journal. This journal has been accepted for indexing on PubMed Central. The manuscript management system is completely online and includes a very quick and fair peer-review system, which is all easy to use. Visit http:// www.dovepress.com/testimonials.php to read real quotes from published authors. 